\title{
Editorial: Peer Governance in Online Communities
}

\author{
Primavera De Filippi ${ }^{1,2 *}$ and Nathan Schneider ${ }^{3}$ \\ ${ }^{1}$ Centre National de la Recherche Scientifique (CNRS), Paris, France, ${ }^{2}$ Berkman Klein Center for Internet and Society, Harvard \\ University, Cambridge, MA, United States, ${ }^{3}$ University of Colorado Boulder, Boulder, CO, United States
}

Keywords: online governance, peer production, digital labor, blockchain, open source

\section{Editorial on the Research Topic}

\section{Peer Governance in Online Communities}

Much of the attention on the governance of online platforms has focused on the power held by large online operators and the challenges they face in governing these platforms: How can they regulate users' behavior and moderate the content that these platforms display? To what extent should they be held accountable for such content?

This Research Topic turns to the under-discussed and under-studied questions of governance within the communities that online platforms host: How do users develop governance rules and informal norms? What is the legitimacy of these rules, and how are they enforced? What is the extent to which users with moderator roles are held accountable for their decisions? What are the sanctions available to these communities?

The governance of the local and the quotidien in online life matters in big ways. Ever since Alexis de Tocqueville chronicled the everyday-ness of early democracy in the United States, it has been evident that people's small-scale associations have something to do with the largest political questions a society faces. The hashtags, the threads, the chat groups with co-workers-these are all spaces where societies are being made and remade. Even the most powerful platform companies can exert control over these spaces only to a point. When we put all our focus on what companies do from the top down, or what regulators impose from the outside, we neglect the generative, creative, and sometimes dangerous politics that can emerge from within communities themselves.

The neglect of attention to governance in online communities has included the software made available to those communities. Almost universally, moderators wield authority without direct accountability to community members. Communities often end up developing ad-hoc governance practices that are not readily enforceable within one platform and are not interoperable among multiple platforms. Although technologies underlying social platforms have advanced rapidly in recent years, the governance technology has too often been stagnant and unimaginative. Taking online governance seriously means not just exploring what platforms can do from the top down and regulators can do from without, but also how communities can better self-govern from within.

This Research Topic emerged through our collaboration in the Metagovernance Project, an organization engaged in research, knowledge-sharing, and software development for advancing online governance. The contributions here reveal the diversity of challenges found in communityscale governance, as well as the innovations that have arisen among communities themselves.

The special edition starts with an analysis of the practices of online peer-production communities for the creation of digital commons, and the way in which they perceive the value of different types of contributions. Focusing on the case of the Drupal community, Rozas et al. challenge the code-centric approach adopted by many peer-production communities, highlighting the need to give more attention to a variety of community-oriented activities, such as participation in face-to-face events, 
mentoring of new members, or organizing local communities. These activities provide significant value, yet they often remain invisible to many of the community members.

With Lozano-Paredes's article, the issue then moves to investigate new governance practices emerging in the Global South. Looking at the informal ridesharing services offered on a variety of social media platforms in Colombia-as an alternative to the more commercial platforms like Uber-Lozano-Paredes analyses the emerging internal governance rules and roles, which do not follow traditional corporate or organisational structures. Drawing from the scholarship on platform cooperativism, he describes the hierarchical relationships that progressively emerge between community managers and community members, as well as the communitarian mechanisms of monitoring and selfdefense.

Designing proper governance structures for online peer-topeer communities can, however, be challenging-especially in light of the wide variety of people and needs that these communities might need to attend to. Because of their distributed nature, many of these online communities rely on technological tools to implement and operationalise their governance structure. Technological innovation can thus lead to institutional innovation, with the emergence of new governance structures that were not possible before. At the same time, technological tools can also be used to benchmark the governance of existing communities. Tchernichovski et al. present a framework for running experiments in order to better understand the benefits and drawbacks of existing tools, and to identify ways of improving on governance in practice. They point to the untapped possibilities of further empirical research on community self-governance.

When designing governance systems for online communities, it is important to recognize that discrepancies in values and opinions can be just as valuable as any attempt at resolving them. While most online communities have developed tools to help community members reach consensus on specific matters, Brekke et al. remind us that conflicting perspectives can be leveraged in order to allow for new possibilities to emerge. Drawing from political theory, the authors turn to the notion of "dissensus" as an approach to better accommodating diversities of opinions-in contrast to the more standard attempts at achieving "consensus" at all cost. They explore cases of dissensus in several types of online communities, including blockchain projects.

Finally, Lindman concludes the issue with an overview of the practical and theoretical governance challenges that blockchain communities are facing today, and how these relate to the earlier challenges faced by open source communities. The paper identifies a series of governance solutions adopted by open source communities and discusses their applicability to the blockchain space, both at the practical and theoretical level. The paper concludes by proposing new avenues for future research in the emerging field of governance technologies, which might provide new insights to both researchers and practitioners in the field.

We are grateful to the contributors to this issue, as well as the reviewers who helped strengthen their work. This issue, we hope, helps demonstrate the promise in continuing to advance research on community-scale self-governance online.

\section{AUTHOR CONTRIBUTIONS}

PF and NS participated equitably in writing this editorial and editing the articles in the topic.

Conflict of Interest: The authors declare that the research was conducted in the absence of any commercial or financial relationships that could be construed as a potential conflict of interest.

Publisher's Note: All claims expressed in this article are solely those of the authors and do not necessarily represent those of their affiliated organizations, or those of the publisher, the editors and the reviewers. Any product that may be evaluated in this article, or claim that may be made by its manufacturer, is not guaranteed or endorsed by the publisher.

Copyright (c) 2021 De Filippi and Schneider. This is an open-access article distributed under the terms of the Creative Commons Attribution License (CC $B Y$ ). The use, distribution or reproduction in other forums is permitted, provided the original author(s) and the copyright owner(s) are credited and that the original publication in this journal is cited, in accordance with accepted academic practice. No use, distribution or reproduction is permitted which does not comply with these terms. 